\title{
Kinetics and Mechanism of the Uncatalyzed Esterification of Acid-Rich Oil with Glycerol
}

\author{
Ke Li $i^{1,2,3,4,5}$, Jie Chen 1,2,3,4,5, Xiaoan Nie $1,2,3,4,5,6$, Jianchun Jiang1,2,3,4,5,6 \\ ${ }^{1}$ Institute of Chemical Industry of Forest Products, CAF, Nanjing, China \\ ${ }^{2}$ National Engineering Laboratory for Biomass Chemical Utilization, Nanjing, China \\ ${ }^{3}$ Key Laboratory of Chemical Engineering of Forest Products, National Forestry and Grassland Administration, Nanjing, China \\ ${ }^{4}$ Key Laboratory of Biomass Energy and Material, Nanjing, China \\ ${ }^{5}$ Jiangsu Co-Innovation Center of Efficient Processing and Utilization of Forest Resources, Nanjing, China \\ ${ }^{6}$ Research Institute of Forestry New Technology, CAF, Beijing, China \\ Email: like@icifp.cn
}

How to cite this paper: Li, K., Chen, J., Nie, X.A. and Jiang, J.C. (2022) Kinetics and Mechanism of the Uncatalyzed Esterification of Acid-Rich Oil with Glycerol. Open Journal of Applied Sciences, 12, 1-9. https://doi.org/10.4236/ojapps.2022.121001

Received: December 4, 2021

Accepted: January 2, 2022

Published: January 5, 2022

Copyright $\odot 2022$ by author(s) and Scientific Research Publishing Inc. This work is licensed under the Creative Commons Attribution International License (CC BY 4.0).

http://creativecommons.org/licenses/by/4.0/

\begin{abstract}
In this paper, non-catalytic high temperature deacidification process of glycerol rich in acid oil was studied. Through orthogonal experiment, the primary and secondary order of influencing factors was temperature, glycerol dosage and reaction time, and the optimal process conditions were further verified: The ratio of fatty acid to glycerol is 1:1.2, the reaction temperature is $240^{\circ} \mathrm{C}$, and the acid value can be reduced to $1.66 \mathrm{mg} \mathrm{KOH} / \mathrm{g}$ for $2 \mathrm{~h}$. In addition, the activation energy of the reaction was $54.93 \mathrm{~kJ} / \mathrm{mol}$ by kinetic study. Combined with the $K_{1}$ value of each reaction, it was confirmed that the temperature rise was conducive to the progress of the reaction. Finally, the high temperature ionization theory of glycerol is put forward, and the mechanism of auto-catalyzed deacidification reaction of glycerol is deduced by using this theory. This theory not only explains this study, but also perfectly explains the slow reaction time of low glycerol dosage.
\end{abstract}

\section{Keywords}

Oil, Fatty Acid, Esterification, Kinetics, Reaction Mechanism

\section{Introduction}

Biodiesel (fatty acid alkyl ester) is a kind of green liquid energy synthesized from renewable oil [1]. Its molecular structure is very similar to existing diesel oil, and it can be mixed or used alone. It not only has good environmental performance [2] [3] [4], but also has good combustion and engine starting performance [5] 
[6] [7]. Raw materials are also widely available, include herbal oils, such as rapeseed oil, corn oil and soybean oil and so on; woody oils, such as tung oil and tallow seed oil and so on; and animal oils such as fish oil. In addition, microbial oils and waste oils are also widely used sources of raw materials [1]. The development of bio-diesel industry has a great strategic significance to energy security, pollution control and sustainable economic development, etc., and has attracted the attention of the governments all over the world [8] [9] [10]. The synthesis of fatty acid methyl ester with high-quality oil (the acid value is less than 4 $\mathrm{mg} \mathrm{KOH} / \mathrm{g}$ ) and methanol under alkali catalysis is the most simple and convenient process (within 2 hours) for the synthesis of biodiesel, but the production of biodiesel with high-quality oil raw materials has a very high raw material cost and has the phenomenon of competition with the public for food, which is highly undesirable [11]. In order to reduce the cost, the use of waste oil or acidified oil has become the best choice [12] [13], which not only reduces the cost of raw materials, but also turns waste into treasure, protecting the environment and food safety (reduce the return of gutter oil to tables). However, such oils with high acid value cannot directly undergo base-catalyzed transesterification due to the presence of a large number of free fatty acids, so esterification and acid reduction are often required in advance [14]. The so-called esterification and acid reduction is the esterification reaction between fatty acids and methanol under acid catalysis to synthesize fatty acid methyl ester. Biodiesel was prepared by transesterification of the oil after acid reduction. In this way, the cost of raw material is reduced, but the esterified oil must separate methanol and remove acid catalyst, which undoubtedly increases the process cost. In order to ignore one or the other, no catalytic esterification using glycerol drop acid has become the new choice [15], glycerin already in the structure of the oil, is a by-product of biodiesel production, so not only avoid the separation of methanol and acid catalyst and the processing of recycled glycerin, the esterification products can be sued directly for the ester exchange reaction, conducive to continuous production, It will greatly promote the development of the industry. However, not all oils with high acid values are suitable for this process, For example, a high acid value may lead to a reaction time up to 8 hours [16]. The previous studies of our research group showed that the most suitable acid-rich oil without catalytic esterification of glycerol should be the acid-rich oil with an acid value of about 10 to more than 100, and the glycerol self-catalytic acid reduction process of acid-rich oil was obtained, and the acid reduction period was less than two hours. However, the process may not be optimal because only sued simple experimental analysis. In addition, the previous studies did not involve the kinetic study of the autocatalytic acid reduction of the acid-rich oil glycerol, no further insight into the reaction mechanism. Therefore, on the previous basis [17], this study has made a further study and discussed the dynamics and mechanism. The optimal process for deacidification of glycerol was obtained through orthogonal analysis, and the activation energy of the reaction was obtained, and 
the mechanism was detailed. It will have high reference value for theoretical research and practical production.

\section{Methodology}

\subsection{Materials and Equipment}

Acid-rich oil (It's a mixture of soybean oil and oleic acid, acid value 56.85 $\mathrm{mgKOH} / \mathrm{g}$ ), soybean oil was purchased from Yihai Grain and Oil industry Co., Ltd (Taizhou, China), Oleic acid was purchased from Sinopharm Chemical Reagent Co., Ltd (Shanghai, China), glycerinum was purchased from Xilong Scientific Co., Ltd (Shantou, China). ZNHW model heating jacket was purchased from Yuhua Instrument Co., Ltd (Gongyi, China), provides heat for the reaction; IKA RW20 digital stirrer, make the material mix evenly; XY Series Precision Electronic Balance was purchased from Xingyun Electronic Equipment Co., Ltd (Changshu, China), used for measure.

\subsection{Method of Autocatalytic Acid Reduction of Glycerol}

Add $120 \mathrm{~g}$ of acid-rich oil and a certain amount of glycerol to a $250 \mathrm{~mL}$ threenecked, round-bottomed flask which provided with a mechanical stirrer, distillation condenser and thermometer. Then heated to the required temperature. For the process experiment, after the reaction to the required time, drop the temperature and measure the acid value; For kinetic experiments, take samples every 30 minutes to determine the acid value of the system, and calculate the conversion rate.

In this study, a three factor and three level orthogonal experiment $\mathrm{L}_{9}\left(3^{3}\right)$ was designed to study the optimal technological conditions for the acid reduction reaction of glycerol, and the specific factor and level design were shown in Table 1.

Among them, according to the acid value of Acid-rich oil, we can calculate that, when the molar ratio of acid and glycerol is 1:1, the corresponding mass is 120:11.04.

\section{Results and Discussions}

\subsection{Optimal Process Condition}

Use the method in Section 2.1, the factor and level in Section 2.2 above. Design 9 groups of orthogonal experiments, study the technology of acid reduction of

Table 1. Factor level design of orthogonal experiment.

\begin{tabular}{lccc}
\hline & \multicolumn{3}{c}{ Level } \\
\cline { 2 - 4 } Factor & 1 & 2 & 3 \\
\hline A. Acid: Gly (molar ratio) & $1: 1$ & $1: 1.3$ & $1: 1.6$ \\
B. Temperature $/{ }^{\circ} \mathrm{C}$ & 200 & 220 & 240 \\
C. Reaction time/min & 90 & 120 & 150
\end{tabular}


glycerol without catalytic. The acid value was taken as the index, and the specific data statistics and calculation results were shown in Table 2.

As can be seen from the data and analysis results in Table 2, the acid value of acid-rich oils can be effectively reduced by glycerol without catalytic, the acid value can be reduced to a level which satisfy the transesterification reaction (less than $2 \mathrm{mg} \mathrm{KOH} / \mathrm{g}$ ). As for the acid reduction of glycerol without catalytic, the main and secondary factors are $\mathrm{B}, \mathrm{A}$ and $\mathrm{C}$. Temperature has the most prominent effect on acid reduction, followed by the amount of glycerol, and the last is time. This just explains the reason why the reaction time is long (8 hours) with less amount of glycerol in the literature [16]. In addition, orthogonal analysis shows that the best parameter combination for acid reduction of glycerol is $\mathrm{A}_{3} \mathrm{~B}_{3} \mathrm{C}_{3}$, that is, $120 \mathrm{~g}$ of acid-rich oil, $11 \mathrm{~g}$ of glycerol, reaction for 2 hours. This is easy to understand, it shows that the increase in the amount of glycerin, the increase in temperature, and the increase in time are in theory favorable for the reaction to proceed in the direction of decreasing the acid value.

Since the reaction temperature is the most influential factor, and in fact, no one is willing to increase the dosage of glycerol, too high dosage of glycerol will undoubtedly increase the cost of raw materials, so to achieve the purpose of rapidly reducing the acid value of acid-rich oils and reduce the feed as far as possible. According to the No. 6 in Table 2, the ratio of fatty acid to glycerol is 1:1.2, the reaction temperature was set at $240^{\circ} \mathrm{C}$, and the reaction was performed at atmospheric pressure for $2 \mathrm{~h}$. After cooling, the acid value of the product was determined to be $1.66 \mathrm{mg} \mathrm{KOH} / \mathrm{g}$. It is lower than all the above experimental results, which indicates that the optimal process is more accurate.

Table 2. Results and data analysis of orthogonal test.

\begin{tabular}{|c|c|c|c|c|}
\hline No. & $A$ & $B$ & $C$ & $\begin{array}{l}\text { Acid value } \\
\text { (mgKOH/g) }\end{array}$ \\
\hline 1 & 1 & 1 & 1 & 12.02 \\
\hline 2 & 1 & 2 & 2 & 3.90 \\
\hline 3 & 1 & 3 & 3 & 2.45 \\
\hline 4 & 2 & 1 & 2 & 11.86 \\
\hline 5 & 2 & 2 & 3 & 2.69 \\
\hline 6 & 2 & 3 & 1 & 2.13 \\
\hline 7 & 3 & 1 & 3 & 7.10 \\
\hline 8 & 3 & 2 & 1 & 2.51 \\
\hline 9 & 3 & 3 & 2 & 1.72 \\
\hline$K_{1}$ & 6.12 & 10.33 & 5.55 & \\
\hline$K_{2}$ & 5.55 & 3.03 & 5.83 & \\
\hline$K_{3}$ & 3.78 & 2.10 & 4.07 & \\
\hline$R$ & 2.34 & 8.23 & 1.76 & \\
\hline
\end{tabular}




\subsection{Kinetics Study}

The esterification reaction of glycerol and fatty acid mainly involves the formation and mutual transformation of monoglyceride, diglycerides and triglyceride. In addition, transesterification reaction between glycerol and triglyceride, and acyl transfer reaction of monoglyceride or diglycerides are also involved in the system. It involves not only many parallel reactions, but also many consecutive reactions, and they are all reversible reactions. So detailed studies are extremely complicated. However, the results in actual production are single, so in order to simplify the kinetic study of esterification reaction of fatty acid and glyceride, it can be studied only from the consumption of fatty acid (acid value). That is, it is assumed that the production of monoglyceride, diglycerides and triglyceride contribute equally to the reduction of fatty acid content and ignores the conversion between them (this is also consistent with the actual apparent results). So, the correlation rate equation of esterification of fatty acids can be expressed as follows:

$$
\begin{aligned}
& r_{y}=k c_{y}^{\alpha} c_{g}^{\beta}=k_{1} c_{y}^{\alpha}=k_{1}\left[c_{y 0}(1-x)\right]^{\alpha} \\
& r_{y}=-\frac{\mathrm{d} c_{y}}{\mathrm{~d} t}=\frac{\mathrm{d}\left[c_{y 0}(1-x)\right]}{\mathrm{d} t}=c_{y 0} \frac{\mathrm{d} x}{\mathrm{~d} t}
\end{aligned}
$$

In the formula, $c_{y}$ is the concentration of fatty acid in the acid-rich oil, $c_{g}$ is the concentration of glycerol (excessive, which can be regarded as a fixed value), $c_{y 0}$ is the initial concentration of fatty acid in the acid-rich oil, and $x$ is the conversion rate of fatty acids;

And the Formulas (1) and (2) available:

$$
\frac{\mathrm{d} x}{\mathrm{~d} t}=\frac{k_{1}}{c_{y 0}}\left[c_{y 0}(1-x)\right]^{\alpha}
$$

That is:

$$
c_{y 0}^{1-\alpha}(1-x)^{-\alpha} \mathrm{d} x=k_{1} \mathrm{~d} t
$$

According to the first-order reaction integral, the $\alpha$ is 1 , so the following equation can be obtained by calculus:

$$
-\ln (1-x)=k_{1} t+C
$$

Thus, the variable of Equation (3) can be determined only by calculating the conversion rate of fatty acids, and the conversion rate of fatty acids can be easily calculated according to the change of acid value:

$x=($ acid value before reaction - acid value after reaction)/acid value before reaction.

Figure 1 shows the kinetics related conversion rates, they were mainly conversion rates at the corresponding time of each experiment, the reaction temperature is $200^{\circ} \mathrm{C}, 210^{\circ} \mathrm{C}$, and $220^{\circ} \mathrm{C}$.

According to the experimental data in Figure 1 and Equation (3), the coordinate diagram of $-\ln (1-x)$ to $t$ was drawn, and the $k_{1}$ values corresponding to 


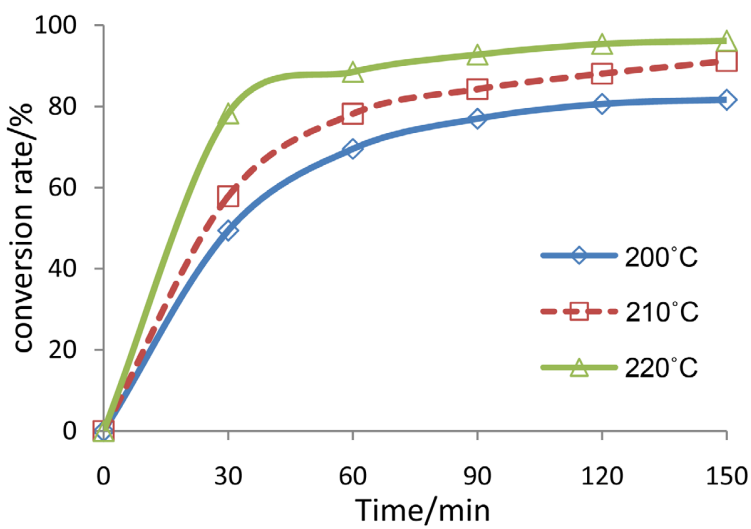

Figure 1. The relationship between conversion rate and time at different temperatures.

different temperatures could be obtained by linear fitting combination, as shown in Figure 2. Finally, according to the Arrhenius formula $k_{1}=A \exp \left(-E_{a} / R T\right)$, take the $\log$ of both sides can get $\ln k_{1}=-E_{a} / R T+\ln A$, draw the coordinate graph of $-\ln k_{1}$ to $1 / T$ and linear fitting, get the equation

$-\ln k_{1}=6607.2 / T-9.2097, R^{2}=0.95$, then get the activation energy $E_{a}=54.93$ $\mathrm{kJ} / \mathrm{mol}$. In addition, it can be seen from the fitting line and $R^{2}$ that it is scientific to study the kinetics of esterification only from the consumption of fatty acids. It can be seen that the increase of temperature is indeed conducive to the process of acid reduction reaction from the increase of $K_{1}$ with the increase of temperature and $E_{a}$.

\subsection{Discussion on Mechanism}

As we all know, esterification of fatty acids and fatty alcohols usually needs to be carried out under the condition of catalyst [18], so how can fatty acids and glycerol react quickly without catalysis? This indicates that the high temperature deacidification of glycerol with fatty acids may be due to the autocatalysis of glycerol. For this reason, we put forward a possible mechanism, as shown in Figure 3. After analysis, it is mainly because:

1) The oxygen atom of the hydroxyl group in glycerol is more electronegative than the carbon atom and has electron-absorbing induction effect, which makes the electrons close to the oxygen atom.

2) The more hydroxyl groups there are, the better they are at absorbing electrons. Glycerol has three hydroxyl groups, which has a strong ability to attract electrons, which further reduces the density of their electron clouds and reduces their binding to hydrogen, making the hydrogen in glycerol more active than that in monoalcohol.

3) At higher temperatures, the hydrogen atoms easily gain enough kinetic energy to escape from the glycerol structure and form free (relatively stable) hydrogen ions, making glycerol somewhat acidic.

So glycerol is very easy to produce hydrogen ions at high temperature, and then play the same catalytic role as acid catalyst. 
So how does glycerin make high acid value oils deacidify more thoroughly? See Figure 4. After analysis, compared with acid catalysis, it may be mainly because:

1) Under the catalysis of acid, hydrogen ions attack carbonyl oxygen to form electron-deficient carbonyl carbon, so that alcohol and its nucleophilic addition. This step is the control step of esterification reaction and the reaction is slow. And then the ester is obtained through rearrangement dehydration and other processes.

2) Under autocatalysis, hydrogen ions will also attack carbonyl oxygen to form electron-deficient carbonyl carbon, but at this time, the nucleophilic addition with it is no longer alcohol, but oxygen anion without hydrogen ions. The group is easier to add to the carbonyl carbon, making the reaction easier; In addition, a series of rearrangement reactions are avoided; the intermediate products can be rapidly dehydrated into esters.

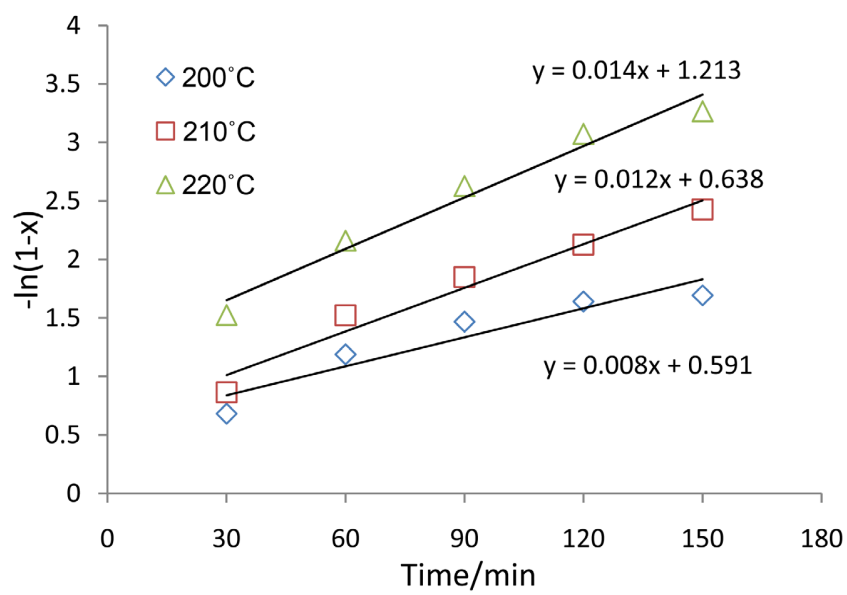

Figure 2. The diagram of $-\ln (1-x)$ to time.

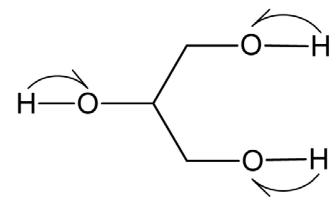

(a)

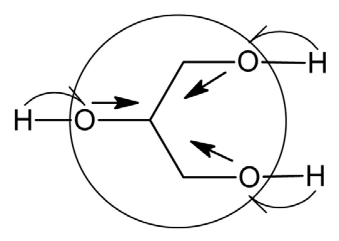

(b)

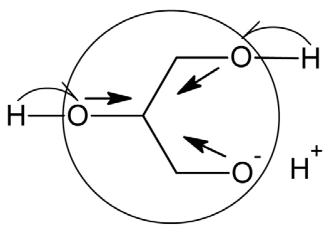

(c)

Figure 3. Mechanism of hydrogen ion formation in glycerol. (a) Single group inductive effect; (b) Mutual induction; (c) Thermal ionization.
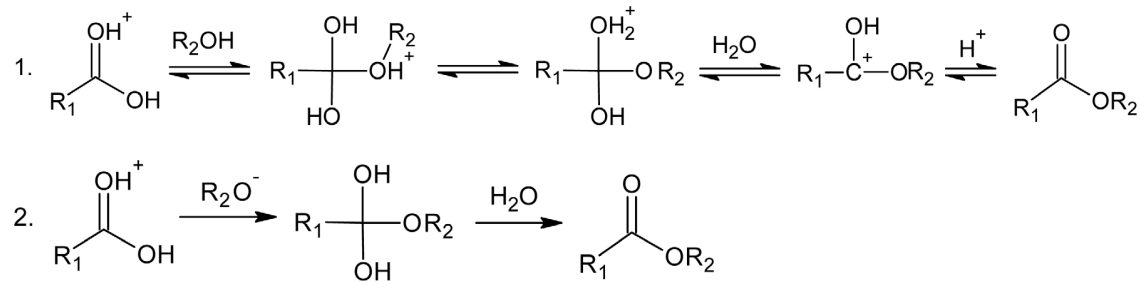

Figure 4. Comparison between acid catalysis and glycerol autocatalysis. 
To sum up, if the glycerol dosage is only slightly higher than fatty acid, a large number of hydrogen ions cannot be formed at the later stage of the reaction, which will make it difficult for the acid value to decrease in the later stage and the reaction time must be long [16]. Therefore, in the case of excess glycerol, a more complete deacidification of fatty acids can be achieved in a short time.

\section{Conclusion}

In this paper, through orthogonal experiment, it is further verified that glycerol can be used to achieve rapid esterification and acid reduction for acid-rich oil without catalysis. It can be concluded that the primary and secondary order of influencing factors is temperature, glycerol dosage and the reaction time, and the optimal process conditions are confirmed in combination with the actual conditions: the ratio of fatty acid and glycerol is $1: 1.2$, the reaction temperature is $240^{\circ} \mathrm{C}$, the reaction time is $2 \mathrm{~h}$, the acid value can be reduced to below $1.66 \mathrm{mg}$ $\mathrm{KOH} / \mathrm{g}$ (The conversion rate is $97.08 \%$ ). In addition, the activation energy of glycerol acid reduction reaction at high temperature was $54.93 \mathrm{~kJ} / \mathrm{mol}$ by kinetic study, and combined with the $K_{1}$ of each reaction, it could be seen that the increase of temperature was indeed conducive to the acid reduction reaction. Finally, through comparative analysis, it is concluded that the deacidification of glycerol with rich-acid oil may be catalyzed by hydrogen ions produced by glycerol at high temperature. By using this theory, the mechanism which can explain the reaction of glycerol autocatalytic deacidification was deduced. This theory not only explains this study, but also perfectly explains the slow reaction time of low glycerol dosage.

\section{Acknowledgements}

The authors are grateful for the National "Thirteenth Five-Year" Plan for Science and Technology Support (Grant number: 2019YFB1504001-02).

\section{Conflicts of Interest}

The authors declare no conflicts of interest regarding the publication of this paper.

\section{References}

[1] Vasudevan, P.T. and Briggs, M. (2008) Biodiesel Production-Current State of the Art and Challenges. Journal of Industrial Microbiology and Biotechnology, 35, 421430. https://doi.org/10.1007/s10295-008-0312-2

[2] Sanches, R.F.E., Yamashiro, M.G.N., Santos, P.L. and Tambor, J.H.M. (2020) Biodiesel e a busca por um equilíbrio entre sociedade, meio ambiente e saúde. Revista Eniac Pesquisa, 9, 345-365. https://doi.org/10.22567/rep.v9i2.735

[3] Homdoung, N., Sasujit, K., Dussadee, N., et al. (2020) Experimental Investigation of a Small Agricultural Diesel Engine Performance Using Community Biodiesel from Wild Trees. Maejo International Journal of Energy and Environmental Communication, 2, 9-16. https://doi.org/10.54279/mijeec.v2i1.244946 
[4] Thers, H., Djomo, S.N., Elsgaard, L., et al. (2019) Biochar Potentially Mitigates Greenhouse Gas Emissions from Cultivation of Oilseed Rape for Biodiesel. Science of the Total Environment, 671, 180-188. https://doi.org/10.1016/j.scitotenv.2019.03.257

[5] Agarwal, A.K., Bijwe, J. and Das, L.M. (2010) Wear Assessment in a Biodiesel Fueled Compression Ignition Engine. Journal of Engineering for Gas Turbines \& Power, 125, 820-826. https://doi.org/10.1115/1.1501079

[6] Atadashi, I.M., Aroua, M.K. and Abdul Aziz, A. (2010) High Quality Biodiesel and Its Diesel Engine Application: A Review. Renewable \& Sustainable Energy Reviews, 14, 1999-2008. https://doi.org/10.1016/j.rser.2010.03.020

[7] Xue, J.L., Grift, T.E. and Hansen, A.C. (2011) Effect of Biodiesel on Engine Performances and Emissions. Renewable \& Sustainable Energy Reviews, 15, 1098-1116. https://doi.org/10.1016/j.rser.2010.11.016

[8] Pousa, G.P.A.G., Santos, A.L.F. and Suarez, P.A.Z. (2007) History and Policy of Biodiesel in Brazil. Energy Policy, 35, 5393-5398. https://doi.org/10.1016/j.enpol.2007.05.010

[9] Ayoub, M. and Abdullah, A.Z. (2012) Critical Review on the Current Scenario and Significance of Crude Glycerol Resulting from Biodiesel Industry towards More Sustainable Renewable Energy Industry. Renewable and Sustainable Energy Reviews, 16, 2671-2686. https://doi.org/10.1016/j.rser.2012.01.054

[10] Krbitz, W. (1999) Biodiesel Production in Europe and North America, an Encouraging Prospect. Renewable Energy, 16, 1078-1083.

https://doi.org/10.1016/S0960-1481(98)00406-6

[11] Zhao, Z.B., Hua, Y.Y. and Liu, B. (2005) How to Secure Triacylglycerol Supply for Chinese Biodiesel Industry. Progress in Biotechnology, 11, 1-6.

[12] Wang, Y., Ou, S.Y., Liu, P.Z., et al. (2006) Comparison of Two Different Processes to Synthesize Biodiesel by Waste Cooking Oil. Journal of Molecular Catalysis A: Chemical, 252, 107-112. https://doi.org/10.1016/j.molcata.2006.02.047

[13] Zhang, H.L., Ding, J.C. and Zhao, Z.D. (2012) Microwave Assisted Esterification of Acidified Oil from Waste Cooking Oil by CERP/PES Catalytic Membrane for Biodiesel Production. Bioresource Technology, 123, 72-77. https://doi.org/10.1016/j.biortech.2012.06.082

[14] Mbaraka, I.K. and Shanks, B.H. (2005) Design of Multifunctionalized Mesoporous Silicas for Esterification of Fatty Acid. Journal of Catalysis, 229, 365-373. https://doi.org/10.1016/j.jcat.2004.11.008

[15] He, S.L., Huang, Z.K. and Zhang, H.L. (2012) Research on Synthesis Technology of PUFAs Glyceride. Journal of Wuhan University of Technology, 34, 34-37.

[16] Liu, P., Jiang, J.C., Chen, S.G., et al. (2016) Deacidification of High Acid Value Waste Oil by Esterification with Glycerol. Applied Chemical Industry, 45, 1242-1245.

[17] Li, K., Chen, J., Nie, X.A., et al. (2022) Fast Deacidification of Acid-Rich Oil by Esterification without Catalysis. Chemistry and Industry of Forest Products, 42.

[18] Zaidi, A., Gainer, J.L. and Carta, G. (2010) Fatty Acid Esterification Using NylonImmobilized Lipase. Biotechnology and Bioengineering, 48, 601-605. 